\title{
PYSTYSUORASTA LÄMPÖTILAN JAKAANTUMISESTA MAAN PINNASTA YLÖSPÄIN JA SEN MERKITYKSESTÄ HALLANTORJUNNASSA
}

\author{
YRJö Pessi \\ Hallakoeasema, Pelsonsuo.
}

Saapunut 10.6. 1955

Maan pinnan läheisten ilmakerrosten pystysuora lämpötilan jakaantuminen on ollut useiden tutkijoiden $(2,5,6,8)$ tutkimusten kohteena, joissa on selvitetty näille lämpöoloille ominaisia piirteitä. Selkeinä vuorokausina tulosäteilytyypin vallitessa korkein lämpötila esiintyy paljaalla alustalla maan rajassa laskien siitä ylös päin. Ulossäteilytyypin vallitessa lämpötila on taas alhaisin maan rajassa ja nousee ylös päin. Kasvipeitteen kohdalla lämpötilan ääriarvot esiintyvät vastaavasti kasviston yläosassa. Lisäksi esiintyy useita eri välimuotoja. Hallailmiön esiintyessä on tällaisella lämpötilan pystysuoralla jakaantumisella erikoinen käytännöllinen merkitys sekä kasvien hallanvaurioita että niiden ehkäisemistä ajatellen. Kun kylmä ilmakerros, joka usein on verraten ohut, muodostuu maan rajaan tai kasvipeitteen kohdalla kasviston yläosaan, aiheutuu tästä vaurioita kasveille. Sen sijaan jo muutaman metrin korkeudella lämpötila saattaa olla hallayönä $0^{\circ}$ yläpuolella. Muutamat hallantorjuntamenetelmät perustuvatkin siihen, että pyritään käyttämään hyväksi ylempänä olevien lämpimämpien ilmakerrosten lämpövarastoa. Kun ilman pystysuoralla lämpötilan jakaantumisella on hallailmiön yhteydessä näin keskeinen asema, on hallakoeasemallakin suoritettu tätä koskevia tutkimuksia. Näissä tutkimuksissa on kiinnitetty huomiota lähinnä hallaöinä vallitseviin lämpöoloihin.

\section{Lämpötilan mittaaminen}

Kesällä 1951 suoritettiin lämpötilanmittaukset alkoholialinarvomittareilla (R. Fuess), joissa jaoitus oli $0.5^{\circ}$ tarkkuudella. Mittarit luettiin kuitenkin $0.1^{\circ}$ tarkkuudella. Mittareissa käytettiin sylinterimäisiä säteilysuojuksia, jotka oli tehty $0.3 \mathrm{~mm}: \mathrm{n}$ paksuisesta alumiinipellistä. Suojuksen pituus oli $7 \mathrm{~cm}$ ja halkaisija $3 \mathrm{~cm}$. Säteilyvirhe on öisin tätä mittaustapaa käyttäen 0.3 sekuntimetrin tuulen vallitessa 
noin $-0.9^{\circ}$ ja 1.5 sekuntimetrin tuulella $-0.7^{\circ}(7)$. Kun tuulen nopeus lisääntyy maan pinnasta ylöspäin yhtälön $\mathrm{v}=\mathrm{v}_{1} \times \mathrm{h}^{\mathrm{a}}$ mukaan, jossa $\mathrm{v}_{1}=$ tuulen nopeus m/sek $1 \mathrm{~m} \mathrm{n}$ korkeudella, $\mathrm{v}=$ tuulen nopeus $\mathrm{h}$ metrin korkeudella, $\mathrm{a}=$ vakio, joka vaihtelee $0.14-0.46$ (3, p. 112), johtuu tästä, että säteilyvirhe pienenee suoritettaessa mittauksia korkeammalla. Kun tuulen nopeuden mittauksia ei tehty minimilämpötilojen muodostumishetkellä, ei lukemien tarkkaa oikaisua voitu suorittaa. Kasviston ylärajassa tuulen nopeus on kuitenkin ollut todennäköisesti alle $1 \mathrm{~m} / \mathrm{sek}$, mistä johtuen kaikkiin lämpötilalukemiin lisättiin $+0.9^{\circ}$. Lukemien oikaisussa ei ole otettu siis huomioon sitä, että tuulen nopeus on ehkä ollut suurempi ylöspäin mentäessä. Muulloin tuulen nopeus mitattiin hyrräanemometrillä.

Kesinä 1953 ja 1954 suoritettiin mittaukset termoelementeillä. Mittauslaitteella saatiin helposti $0.1^{\circ}$ lukematarkkuus, sillä $0.1^{\circ}$ lämpötilan poikkeama vastasi galvanometrin asteikolla $1 \mathrm{~mm}: \mathrm{n}$ poikkeamaa. Termoelementin muodosti muovipäällysteinen kupari-konstantaanijohtopari, johtimien läpimitan ollessa $0.5 \mathrm{~mm}$. Kaapelien maksimipituus oli $25 \mathrm{~m}$. Juotoskohdat suojattiin auringon säteilyltä hiukan kaarevaksi taivutetulla Budig-suojuksella, jonka läpimitta oli $7 \mathrm{~cm}$. Maan rajassa ei kuitenkaan säteilysuojuksia käytetty, vaan suojattiin tuntoelin tällöin mittauksen aikana noin 0.5 m:n etäisyydellä olevalla pahvilevyllä. Kesällä 1953 suojattiin juotoskohta lakalla. Seuraavana kesänä muutettiin rakennetta siten, että päällys poistettiin johtimien päältä $3 \mathrm{~cm}: n$ matkalta juotoskohdasta lähtien, paljastuneet johtimet lakattiin ja maalattiin valkoiseksi juotoskohta mukaanluettuna.

Tällaisen Budig-suojuksella varustetun termoelementin säteilyvirhettä ei tutkittu. Muiden tutkijoiden $(2,4,8)$, suorittamien säteilyvirhettä koskevien tutkimusten mukaan säteilyvirhe on todennäköisesti tätä mittaustapaa käyttäen alle $0.2^{\circ}$. Vuonna 1953, jolloin muovipäällys alkoi välittömästi juotoskohdasta lähtien, on johtimia pitkin saattanut tapahtua lämmön johtumista juotoskohtaan aiheuttaen pienen virheen. Oikaisuja lämpötilalukemiin ei kuitenkaan tehty, sillä tutkimusten tarkoitusta ajatellen mainitut virhelähteet olivat merkityksettömiä.

Kesällä 1951 lämpömittarit sijaitsivat $5 \mathrm{~cm}$ maan pinnan yläpuolella, kasviston ylärajassa sekä tästä $0.5,1.0,1.7$ ja 3.0 metrin korkeuksilla. Mittarit sijaitsivat valkoiseksi maalattuun rimaan kiinnitetyissä metallilankakannattimissa (kuva 1) Kesällä 1953 termoelmnit sijaitsivat maan rajassa, $0.3,0.4,2,4,6,8$ ja 11 metrin korkeuksilla sekä kasviston ylärajassa. Kesällä 1954 sijoituskorkeudet olivat maan raja, kasviston yläraja, 2, 4, 8 ja $16 \mathrm{~m}$. Termoelementit sijaitsivat noin $25 \mathrm{~cm}$ :n etäisyydellä vaaleasta pystysuorasta riu'usta sen eteläpuolella (kuva 2). Lämpötilahavainnot suoritettiin kolmena mittaussarjana ja lämpötilalukemaksi otettiin näiden havaintojen keskiarvo.

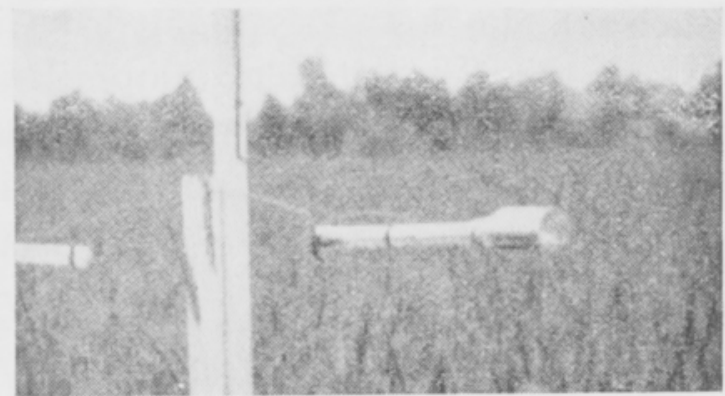

Kuva 1. Alinarvomittareiden kiinnittäminen. Fig. 1. The fastening of the minimum thermometers. 


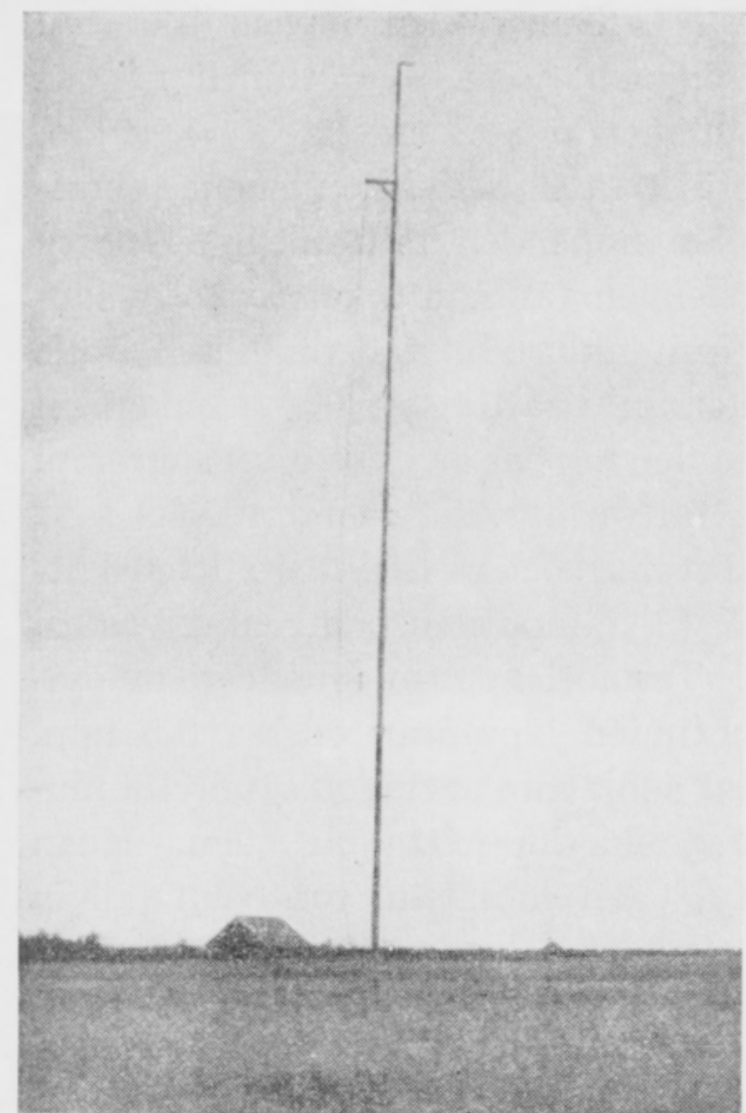

Kuva 2. Masto, jolla termoelementit on nostettu eri korkeuksille.

Fig. 2. The mast, with which the thermocouples have been raised up.

\section{Tutkimustulokset}

Tutkimukset suoritettiin Pelsonsuon laajoilla ja tasaisilla viljelysalueilla, jotka aikaisempien vuosien tutkimusten mukaan ovat erittäin homogeenisia lämpöolojensa puolesta. Lämpötilan pystysuora jakaantuminen vuorokauden muutamina ajankohtina 14-15. VI 1954 ilmenee kuvasta 3. Mittauspaikalle oli kevätmuokkauksen jälkeen kylvetty ohra. Vilja oli juuri orastunut eikä varjostanut vielä maan pintaa. Turve oli verrattain heikosti maatunutta eikä kivennäismaata oltu käytetty maanparannusaineena.

Lämpötilakäyristä ilmenee selvästi tuloja ulossäteilytyypille ominainen lämpötilan pystysuora jakaantuminen (vrt. 2, 5, 8). Lämpötilan jakaantumiselle päivällä on ollut ominaista, ettei lämpötilaeroja ole esiintynyt sanottavasti $4 \mathrm{~m}$ :stä ylöspäin. Sen sijaan tästä alas päin lämpötilagradientti muodostuu suureksi. Maan pinnan lähellä mitattiin klo $13+34.4^{\circ}$ lämpötila, mutta se olisi kohonnut vieläkin suuremmaksi, ellei pilvipeite puolen päivän jälkeen olisi esiintynyt

niin runsaana $(5-7 \mathrm{Ci}, \mathrm{Cu})$. Lämpötila nousee ulossäteilytyypin vallitessa sen sijaan jatkuvasti vielä 4 m:n yläpuolella. Käyrästä 3 (kuva 3) havaitaan, että tulosäteilytyyppi muuttuu ulossäteilytyypiksi noin kaksi tuntia ennen auringon laskua. Käyrästä 4 ilmenee, että auringon laskiessa on lämpötila laskenut lähellä maan pintaa jo alle $-1^{\circ}$. Edelleen havaitaan, että klo 22 ja 1 välillä lämpötilan lasku on ollut vähäisin maan pinnan lähellä. Erikoisesti voidaan panna merkille hallantorjuntatoimenpiteitä ajatellen, että nopein lämpötilan lasku maan pinnan läheisissä ilmakerroksissa tapahtuu jo ennen auringon laskua.

Kuvassa 4 esitetään lämpötilan pystysuora jakaantuminen ulossäteilytyypin vallitessa muutamina selkeinä vuorokausina. Kaikki mittaukset on suoritettu viljelyksellä, jossa on kasvanut kevätvilja. Kuvasta havaitaan, että useimpina öinä pystysuorat lämpötilaerot ovat olleet huomattavia. Kuitenkin esiintyy myös öitä, jolloin pystysuorat lämpötilaerot ovat olleet melko vähäisiä. Tällaisia öitä ovat olleet 11. IX 1951 sekä 6. IX 1953. Taulukosta 1 ilmenee, että lämpötilan nousu on ollut kolmen ensimmäisen metrin matkalla verrattain suuri kahta edellä mainittua yötä lukuunottamatta. Esimerkiksi taulukon kolmena viimeisenä yönä tämä nousu on ollut keskimäärin suurempi kuin 12 seuraavan metrin matkalla. 


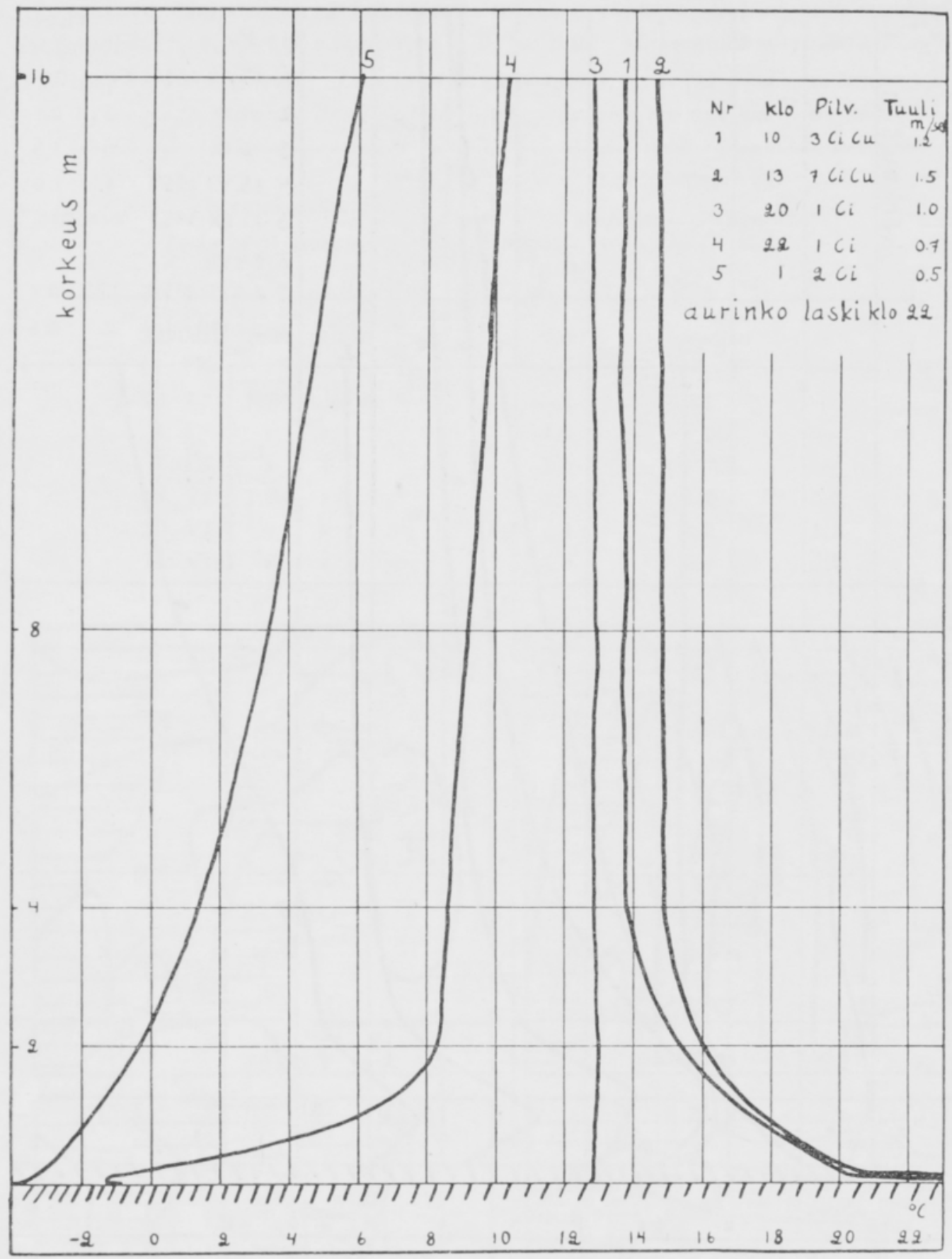

Kuva 3. Ilman lämpötilan pystysuora jakaantuminen muutamina ajankohtina $14-15$. VI 1954 Pelsonsuolla.

Fig. 3. The vertical dividing of the temperature at some time 14-15. VI 1954 in Pelso.

\section{Ilman pystysuoran lämpötilan jakaantumisen merkitys hallantorjunnassa}

Hallayönä, jolloin pystysuora lämpötilagradientti on muodostunut siksi suureksi, että lämpötila on jo $3-5$ metrin korkeudesta lähtien 0 -asteen yläpuolella, tulee mahdolliseksi käyttää hyväksi näitä korkeammalla olevia lämpimämpiä i lmakerroksia kasvien hallanvaurioiden estämisessä. Sen sijaan silloin, kun pysty- 


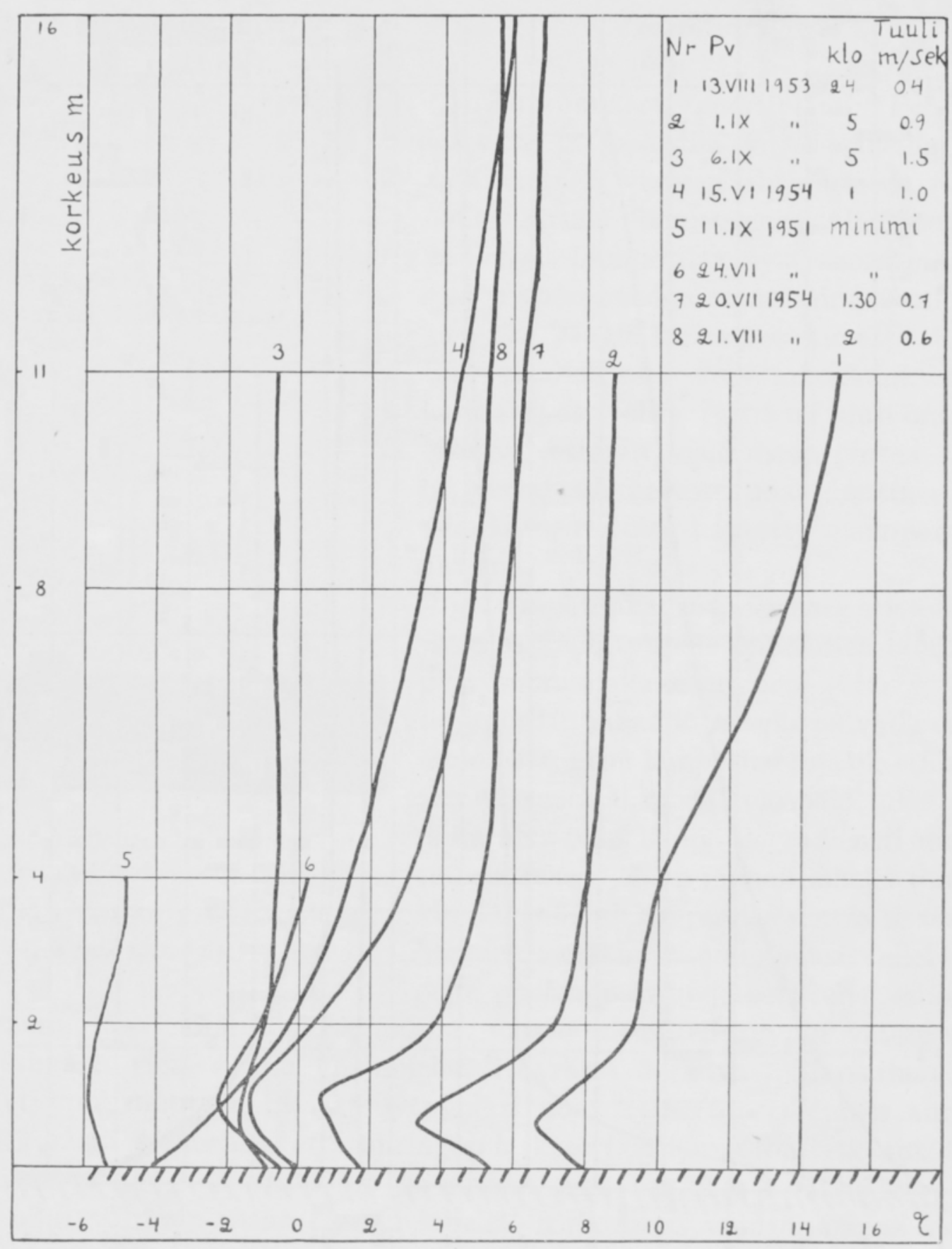

Kuva 4. Ilman lämpötilan pystysuora jakaantuminen muutamina öinä Pelsonsuolla.

Fig. 4. The vertical dividing of the temperature at some nights in Pelso.

suora lämpötilaero on vähäinen (11. IX 1951 ja 6. IX 1953, kuva 4), ei hallantorjuntamenetelmillä, jotka perustuvat ylempien ilmakerrosten lämpövaraston hyväksikäyttöön, ole käyttömahdollisuuksia. Tällainen tilanne vaikeuttaa myös monien muiden hallantorjuntakeinojen menestyksellistä käyttöä. Ei voida olettaa, että tehoisan ulossäteilyn vähentämisellä on tällöin suurtakaan merkitystä varsinkaan silloin, kun lisäksi esiintyy voimakkaita advektioita (6. IX 1953, kuva 5). Näin ollen sellaiset hallantorjuntakeinot, jotka perustuvat tehoisan ulossäteilyn 
Taul. 1. Pystysuoria lämpötilaeroja kahdeksana selkeänä yönä. $t_{0}=$ lämpötila minimin esiintymiskorkeudella, $t_{3}, t_{10}$ ja $t_{15}=$ lämpötila 3,10 ja $15 \mathrm{~m}: n$ korkeudella minimistä ylöspäin.

Table 1. The temperature differences of air at eight clear nights. $t_{0}=$ the minimum temperature, $t_{3}, t_{10}$ and $t_{15}=$ the temperature 3,10 and $15 \mathrm{~m}$ upwards from the minimum temperature.

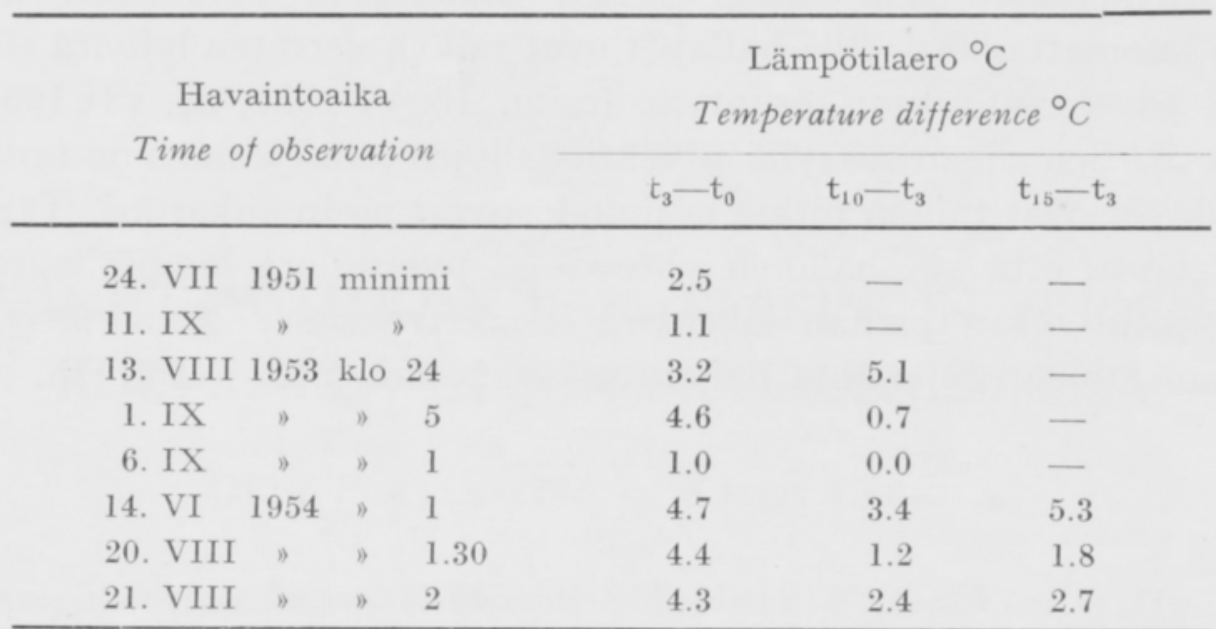
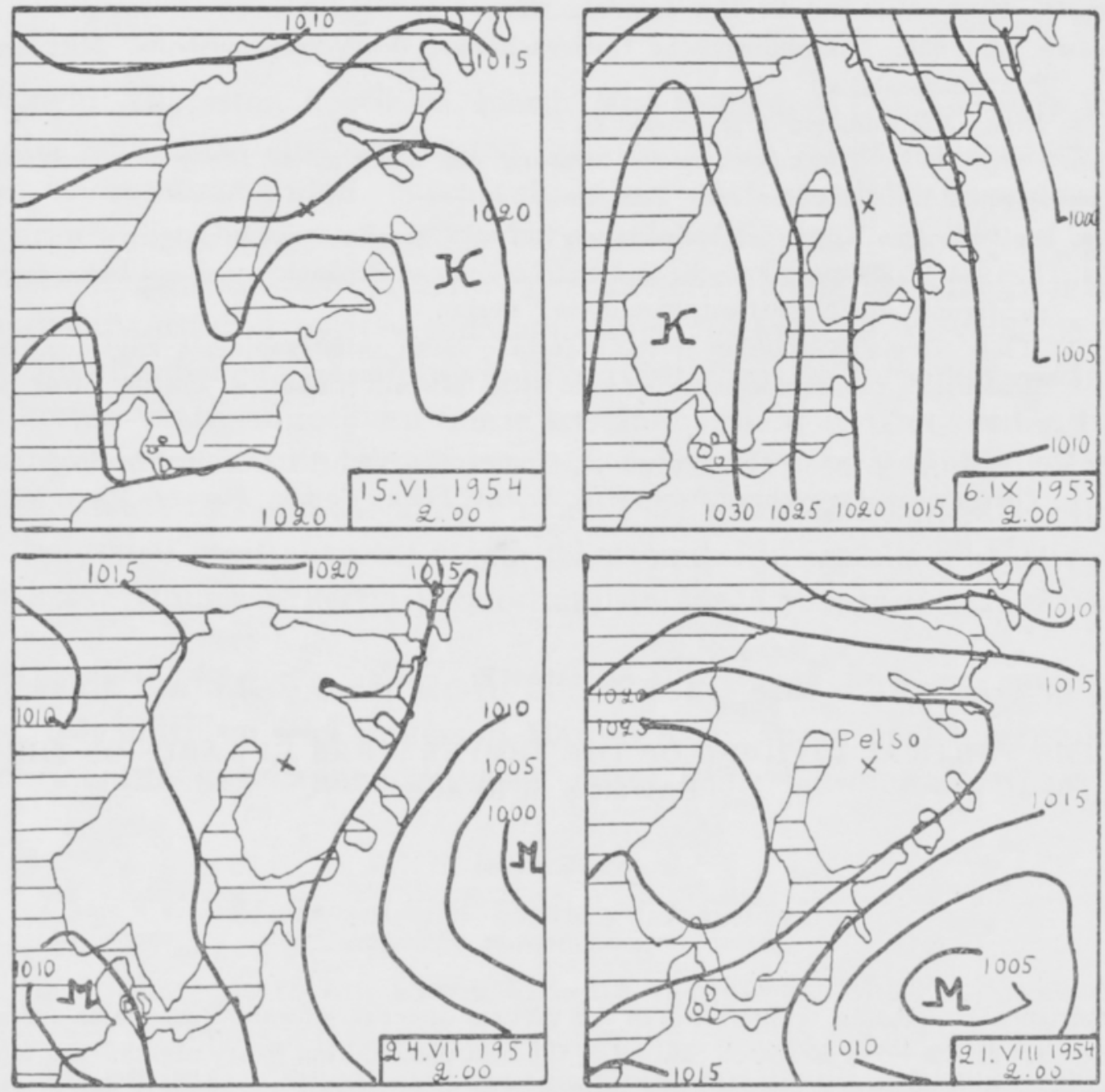

Kuva 5. Isobaarikartat neljältä vuorokaudelta. Gradienttituuli Pelsonsuolla on 6. IX 1953 noin $1.7 \mathrm{~mm}$. Muulloin gradienttituuli erittäin heikko.

Fig. 5. The maps of the atmospheric pressure of four days. The gradientwind is in Pelso $6.1 X 1953$ about $1.7 \mathrm{~mm}$. At another time the gradientwind is very weak. 
pienentämiseen, ovat jokseenkin tehottomia. Lisäksi tehoisan ulossäteilyn vähentäminen mm. sumutusmenetelmiä käyttäen tuottaa teknillisestikin vaikeuksia advektiohallojen yhteydessä.

Ilman pystysuora lämpötilagradientti muodostuu tavallisesti kesähallojen yhteydessä huomattavaksi, sillä hallayöt ovat tällöin verraten lyhyitä eikä hallojen yhteydessä advektioita juuri esiintyne (esim. 15. VI 1954, 24. VII 1951, 21. VIII 1954, kuva 5). Sen sijaan syksyllä advektiohallojen esiintyminen on tavallisempaa. Samoin hallayöt ovat tällöin pitkiä ja muodostuvat usein ankariksi. Tämän vuoksi on odotettavissa, että syyshallojen yhteydessä pystysuora lämpötilagradientti on tavallisesti pieni maan pinnan läheisissä ilmakerroksissa. Näin ollen joudutaan tällöin kiinnittämään huomiota hallantorjuntamenetelmän valintaan.

KIR JALLISUUSLUETTELO

(1) Budig, W. 1914. Veröff. d. Pr. Met. Inst. N:o 294.

(2) Franssila, M. 1936. Mikroklimatische Untersuchungen des Wärmehaushalts. Mitt. der Meteor. Zentralanstalt, 20.

(3) —- 1949. Mikroilmasto-oppi. Helsinki.

(4) Gehlmoff, K. 1922. Thermoelektrische Messung des nächtlichen Temperaturverlaufes in den unteren Luftschichten. Met. Zeitschr.

(5) Geiger, R. 1942. Das Klima der bodennahen Luftschicht. Braunschweig.

(6) Homén, Th. 1894. Bodenphysikalische und meteorologische Beobachtungen mit besonderer Berücksichtigung des Nachtfrostphänomens. Berlin.

(7) PESSI, Y. 1954. Ilman lämpötilan mittaamisesta erilaisia säteilysuojuksia käyttäen. Summary: Measuring the temperature of air with different radiation shields. Maat. aikak. 26, p. $195-197$.

(8) Rossi, V. 1943. Uber mikroklimatologische Temperatur-und Feuchtigkeitsbeobachtungen mit Thermoelementpsychrometerr. Sos. Scient. Fenn., Comm. Phys. - Vath. VI, 25.

SUMMARY:

THE VERTICAL DIVIDING OF THE TEMPERATURE UPWARDS OF THE EARTH'S SURFACE

YRJö Pessi

Frost Research Station, Pelsonsuo

\footnotetext{
Measurements of the air temperature in the vertical direction upwards from earth's surface have been carried out at the Frost Research Station in the first place during frosty nights. The temperature differences of air have been in the middle of the summer so great, that it is possible in practice to prevent the frost injury so, that there will be transfered air from above downwards. On the other hand the temperature differences could be in the autumn very little.
} 